\title{
The influence of site characteristics on the leaf-to-sapwood area relationship in chestnut trees (Castanea sativa Mill.)
}

\author{
Eric Gehring ${ }^{1,2,3}{ }^{(\mathbb{D}} \cdot$ Gianni Boris Pezzatti $^{1} \cdot$ Patrik Krebs $^{1} \cdot$ Stefano $^{1}$ Mazzoleni $^{3}$. \\ Massimiliano Zappa ${ }^{4} \cdot$ Marco Conedera $^{1}$
}

Received: 17 November 2015/Accepted: 25 July 2016/Published online: 2 August 2016

(C) Springer-Verlag Berlin Heidelberg 2016

\begin{abstract}
Key message Biomass allocation in Castanea sativa varies according to the environmental conditions. Specifically, leaf-to-sapwood area ratio is higher on sites with good water supplies and lower in water-stressed conditions.

Abstract Ecological plasticity allows organisms to adapt and to cope with environmental conditions. This is a key trait for species with long live span, which will probably be more vulnerable to changing climate because of their lower adaptation potential via natural selection. We studied the case of the sweet chestnut tree, a naturalized forest species in many European mountain areas, where it grows on very different climates and sites. This raises the question of its adaptation capacity to very different environmental conditions. To test this hypothesis, we applied the pipe model
\end{abstract}

Communicated by U. Luettge.

Electronic supplementary material The online version of this article (doi:10.1007/s00468-016-1447-9) contains supplementary material, which is available to authorized users. approach for analysing the variation in the leaf-to-sapwood area ratio $\left(A_{\mathrm{L}}: A_{\mathrm{S}}\right)$ in 82 chestnut trees growing in very different site conditions (e.g., water-stressed convex vs. water-rich concave sites). We used linear regression analyses to model the $A_{\mathrm{L}}: A_{\mathrm{S}}$ relationship to environmental and dendrometric parameters. Results confirm that $A_{\mathrm{L}}: A_{\mathrm{S}}$ is significantly higher when trees grow on good nutrient- and water-supplied concave sites with respect to water-stressed, convex sites. Chestnut trees are thus able to vary their biomass allocation between sapwood and leaves to adapt their hydraulic characteristics to the site conditions. Trees seem to react to water-stressed conditions by allocating more biomass in the sapwood in respect to the leaves. $A_{\mathrm{L}}: A_{\mathrm{S}}$ may thus represent a useful indicator of tree species plasticity and their adaptation potential to different environmental and climate conditions.

Keywords Autoecology $\cdot$ Ecological plasticity $\cdot$ Hydraulic architecture · Pipe model $\cdot$ Resource allocation $\cdot$ Water availability

Insubric Ecosystem Research Group, WSL Swiss Federal Research Institute, a Ramél 18, 6593 Cadenazzo, Switzerland

2 Laboratory of Soil Biology, University of Neuchâtel, EmileArgand 11, 2000 Neuchâtel, Switzerland

3 Dipartimento di Agraria, University of Naples Federico II, Via Università 100, 80055 Portici, Naples, Italy

4 Hydrological Forecasts Research Group, WSL Swiss Federal Research Institute, Zürcherstrasse 111, 8903 Birmensdorf, Switzerland 


\section{Introduction}

Ecological plasticity results from the combination of genetic variability, environmental effects, and their interactions (Schlichting 1986; Martinez-Vilalta et al. 2009). This is a key adaptive trait for species with long generation times, which will probably be more vulnerable to changing climatic and environmental conditions because of their slower adaptation via natural selection (Hoffmann and Sgrò 2011). Understanding ecological plasticity is thus of paramount importance to predict tree species responses to climate change (e.g., Parmesan 2006). In particular, it is believed that in the future, the water resource may become an even more limiting factor in many ecosystems (e.g., Dai 2012) and species with a higher plasticity will have better chances to overcome future environmental changes.

At local scale, an important characteristic related to water-use efficiency is the ability of changing the biomass allocation between sapwood and leaves as a function of the specific site conditions and water availability in particular (Bonan 2002). In the case of a gradual rising of global temperature and the related water stress, increasing the resource allocation in the absorbing root system and in conductive sapwood may be a strategy to maintain a sufficient hydraulic conductivity to face the decreasing water availability. As postulated by Shinozaki et al. (1964a, b) and verified on different species (Vertessy et al. 1995; Cruiziat et al. 2002; Gehring et al. 2015), the leaf-to-sapwood area ratio $\left(A_{\mathrm{L}}: A_{\mathrm{S}}\right)$ is constant for single portions of a tree crown and reflects the individual hydraulic characteristics of a tree, since it is the result of the energy and biomass investment in water absorbing, conducting, and transpiring tissues (e.g., Vertessy et al. 1995; Cruiziat et al. 2002). Furthermore, such physiological balance varies among trees of the same species as a function of the environmental conditions and local climate (Whitehead et al. 1984; Callaway et al. 2000; Martinez-Vilalta et al. 2009) and tends to be lower for individuals growing on poor and dry soils (Mazzoleni 1990; Mencuccini and Grace 1994; Sterck et al. 2008). Such a low $A_{\mathrm{L}}: A_{\mathrm{S}}$ (which is reflected by an enhanced proportion of sapwood supplying water to leaves) associated with the leaf-specific conductivity may help trees growing in water-stressed conditions to maintain a sufficient water potential gradient and to avoid xylem cavitation (Maherali et al. 2004).

The chestnut tree (Castanea sativa Mill.) is a particularly interesting example in this matter, having the species being diffused and maintained in groves created by man in many mountainous regions of Europe over the past 2000 years (Conedera et al. 2004). In fact, such an active spread and active management has resulted in a broad diffusion of the species at a continental scale and in its establishment until the limits of the potential ecological range (Conedera et al. 2004). Despite such a heavy human imprinting, recent studies on the European chestnut diversity highlighted a high genetic and morphologic differentiation that is similar to other naturally dispersed European tree species, such as the deciduous oaks (Villani et al. 1992; Lauteri et al. 2004; Fernandez-Lopez et al. 2005; Mattioni et al. 2008; Martin et al. 2010; Beccaro et al. 2012; Mattioni et al. 2013). Furthermore, the need to adapt to very contrasting habitats resulted at continental scale in high physiological differentiation of water-use efficiency traits, such as the stomatal sensitivity to water stress limitations (Lauteri et al. 1997, 2004).

In this study, resting on the results of Gehring et al. (2015), we verify the hypothesis of existing variations in $A_{\mathrm{L}}: A_{\mathrm{S}}$ among chestnut trees growing in different site conditions. We in particular analysed variations in $A_{\mathrm{L}}: A_{\mathrm{S}}$ as a function of water supply-related environmental characteristics, such as microtopography, slope, aspect, solar insolation, and distance to next water channel, as well as dendrometric and other tree-related characteristics, such as height, diameter at breast height, crown height, and crown exposure to the light of trees.

\section{Materials and methods}

\section{Study area}

The chestnut area of Canton of Ticino covers ca. 15,000 ha at elevations below $1200 \mathrm{~m}$ a.s.l. (Fig. 1).

The geology of the area is dominated by siliceous rocks with small spots of limestone. Resulting soils are generally classified as haplic podzol or cryptopodzol, consisting in well drained, permeable, and unmottled sandy (clay fraction is usually less than $10 \%$ ) layers and a very consistent and stable organic matter component (Blaser et al. 2005). The main rooting zone covers the uppermost $30 \mathrm{~cm}$ of the mineral soil, whereas sparsely distributed roots are found at depths up to $2 \mathrm{~m}$. Due to the soil permeability, water supply highly depends on the microtopography and tends to form a marked increasing gradient from the water-drained ridges to the water-enriched depressions (Blaser 1973).

The area is characterized by a mild (Insubrian) climate with mean annual precipitation around $1800 \mathrm{~mm}$ and mean annual temperature around $12{ }^{\circ} \mathrm{C}$ (MeteoSwiss climatic normals 1981-2010; http://www.meteoswiss.admin.ch/ home/climate/past/climate-normals.html). During the wet and warm summers, periods without rain are interspersed with heavy precipitation events. When a prolonged dry period is accompanied by high summer temperature, drought-related damages, such as it was the case during the 


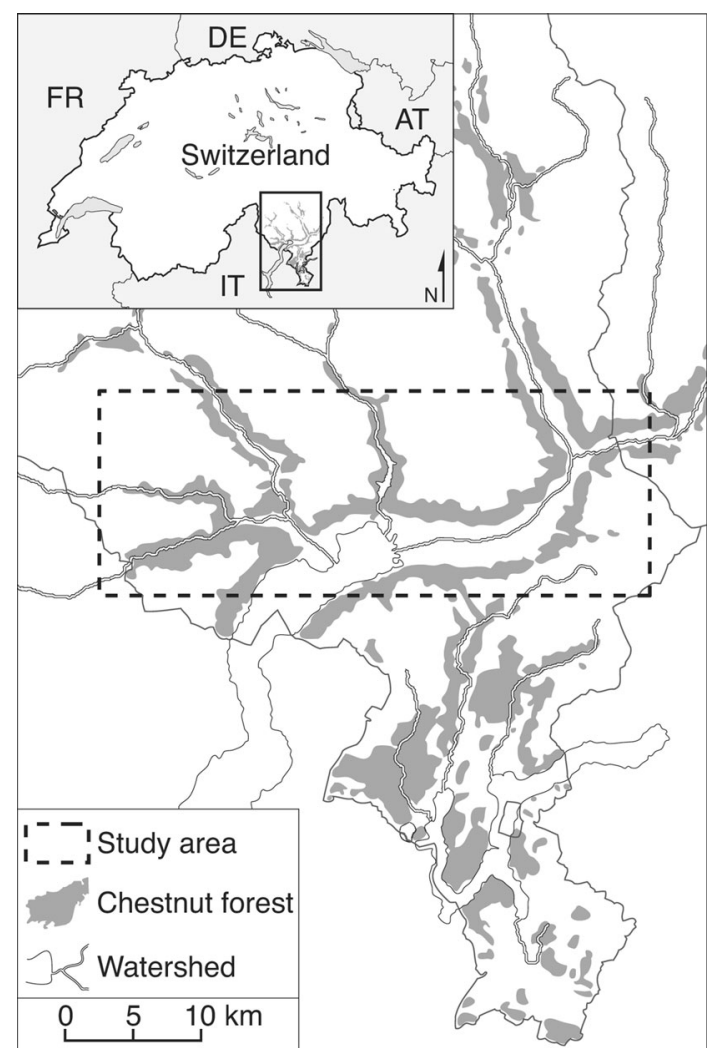

Fig. 1 Study area. Subfigure in the top-left corner shows the location of the study area (small bold rectangle) with respect to Switzerland

extreme hot summer season of 2003 (Spinedi and Isotta 2004) in the most exposed chestnut forests, can occur (Conedera et al. 2010; see also mean values of the aridity index calculated for the study site following UNEP (1992) in Fig. S1 of the Online Resource 1).

The chestnut (Castanea sativa) was first cultivated (and probably first introduced) in the area by the Romans nearly 2000 years ago (Conedera and Krebs 2008) and became an anthropogenic monoculture, occasionally interrupted by the presence of other broad-leaved species, such as Tilia cordata, Quercus petraea, Q. pubescens, Alnus glutinosa, Prunus avium, Acer spp., or Fraxinus spp. Due to its high economical value and broad and intense cultivation in the past (Krebs et al. 2012), chestnut trees are nowadays still present mostly as naturalized stands in areas with extremely varying microtopographic and water supply conditions.

\section{$A_{\mathrm{L}}: A_{\mathrm{S}}$ relationship in $C$. sativa}

The postulate of the pipe model approach for $C$. sativa has been verified by Gehring et al. (2015) in the same study area. The study confirmed the constancy of the $A_{\mathrm{L}}: A_{\mathrm{S}}$ ratio within a branch, highlighting, however, variations within the same tree between different types of branches that is architectural crown branches vs. epicormic shoots (reiterations). Reiterations in particular showed an enhanced sturdiness with respect to crown branches. Furthermore, within-tree differences exist among architectural crown branches as a function of the branch insertion height. For this reason, Gehring et al. (2015) introduced the notion of $A_{\mathrm{L}}: A_{\mathrm{S}}$ of a hypothetical architectural crown branch at ground level $\left(A_{\mathrm{L}}: A_{\text {Sground }}\right)$ as a sampling height-independent parameter allowing to compare $A_{\mathrm{L}}: A_{\mathrm{S}}$ ratios among different trees of the same species.

Since in our study we applied the leaf area-to-sapwood area approach on trees growing in extremely different environmental conditions and it was not possible to set a standardized sampling height. We, therefore, used both $A_{\mathrm{L}}: A_{\mathrm{S}}$ and the branch height-transformed $A_{\mathrm{L}}: A_{\mathrm{Sground}}$ as proposed by Gehring et al. (2015). In fact, without converting the effective measured $\mathrm{A}_{\mathrm{L}}: \mathrm{A}_{\mathrm{S}}$ of the sampled branches to the theoretical $A_{\mathrm{L}}: A_{\mathrm{Sground}}$, any variation in response to environmental ecological factors could be masked by tree internal hydraulic constraints due to the different maximum heights of the sampled individuals. Using the branch height-transformed $A_{\mathrm{L}}: A_{\text {Sground }}$, possible tree internal effects are minimized, allowing a direct comparison among trees displaying a great variability in height due to the differing growing site conditions (small trees on dry sites vs. tall trees on water-rich sites).

\section{Sampling}

Sample trees were selected within a radius of $10 \mathrm{~km}$ at altitudes ranging from 221 to $591 \mathrm{~m}$ a.s.l. to keep climatic and geological conditions as homogeneous as possible. On the contrary, tree selection targeted the highest possible gradient in terms of topography, from extreme waterstressed (e.g., trees growing on rocky ridges, ridges, and steep slopes) to extreme water-supplied (e.g., trees in terrain depressions or near a stream) sites. A total of 82 fully developed (adult) trees from natural regenerated stands were selected (Fig. 1), covering a height range from 1.5 (on extremely unfavourable sites) to $26.6 \mathrm{~m}$ (favourable sites) and a DBH range from 5 to $96 \mathrm{~cm}$, respectively (Table 1). Each sampled tree was characterized using different dendrometric and site-related geo-physiographic (environmental) parameters (Table 2).

\section{Data collection and analysis}

From June 7 to August 13, 2009 and from June 16 to July 22,2010 , one ( 26 cases) or two branches ( 56 cases) per tree were collected from the top region of the crown, depending on its heterogeneity (symmetry and light exposure) and making sure that all leaves were fully developed and without damage from weather (e.g., hale), parasites or 
phytophagous insects. In particular, only crown branches were taken into consideration, avoiding epicormic shoots that have different hydraulic and $A_{\mathrm{L}}: A_{\mathrm{S}}$ characteristics (Gehring et al. 2015).

Table 1 Area, trees, and branches

\begin{tabular}{lcllll}
\hline & Number & Variables & Min & Mean & Max \\
\hline Area & \multirow{2}{*}{1} & Elevation (m a.s.l.) & 221 & 416 & 591 \\
& & Slope (\%) & 0 & 41 & 100 \\
Trees & \multirow{2}{*}{82} & Height (m) & 1.5 & 10.1 & 26.6 \\
& & DBH (cm) & 5 & 40 & 96 \\
Branches & \multirow{2}{*}{142} & Length (cm) & 25 & 122 & 251 \\
& & $\varnothing$ at cutting point (mm) & 7.6 & 18.9 & 37.8 \\
\end{tabular}

The variable values refer to the whole data set (2009 and 2010)
Branches on tall trees were accessed using tree-climbing techniques, cut, and carefully lowered to the ground with a rope. The collected branches were processed in the same day as the cutting to preserve the original form and colour of the leaves. All leaves were then detached and digitized with a scanner (Xerox 9001 machine resolution 200 dpi, contrast +1 , coloured photo quality) to accurately measure their area with the image-processing program Image Pro plus 6.0 (IPP).

Minimum and maximum branch diameters were measured with a calliper $1 \mathrm{~cm}$ before the nearest branching from the cutting point. The cross-sectional area was calculated from the two diameters using the ellipse formula. The presence of heartwood was checked on the dry branch samples using the soap bubble technique as described by Hoadley (1980). The soap bubble

Table 2 Dendrometric and geo-physiographic parameters considered for each tree

\begin{tabular}{|c|c|c|}
\hline Parameter & Unit/values & Notes \\
\hline \multicolumn{3}{|l|}{ Dendrometric parameters } \\
\hline \multirow[t]{4}{*}{ Social position } & Predominant (1) & \\
\hline & Dominant (2) & \\
\hline & Co-dominant (3) & \\
\hline & Dominated (4) & \\
\hline Height & $\mathrm{m}$ & Measured with a tape measure \\
\hline $\mathrm{DBH}$ & $\mathrm{cm}$ & Obtained dividing the stem circumference by $\pi$ \\
\hline Crown base height & $\mathrm{m}$ & Measured with a tape measure \\
\hline Crown exposure to light & $\%$ & Visually estimated in $\%$ \\
\hline \multicolumn{3}{|l|}{ Environmental parameters } \\
\hline Geographic coordinates & CH1903_LV03 projected coordinate system (m) & GPS Trimble, Geoexplorer 2005 series GeoXh \\
\hline Solar insolation & $\mathrm{kJ} / \mathrm{m}^{2} /$ year & Extracted from ArcGIS \\
\hline Slope orientation & $\begin{array}{l}0=\text { southwest facing (more xeric) } \\
2=\text { northeast facing (more mesic) }\end{array}$ & $\begin{array}{l}\text { According to cardinal points and transformed } \\
\text { using Beers et al. (1966) equation, } \\
\sin (A+45)+1 . A=\text { azimuth of the branch }\end{array}$ \\
\hline Elevation & m a.s.l. & Extracted from DEM \\
\hline Slope & $\%$ & Clinometer Meridian MG-3002 \\
\hline Distance to water channel & $\mathrm{m}$ & Laser distance-meter Leica, Disto Classic \\
\hline Vertical microtopography & $\begin{array}{l}\text { Hump }(-1) \\
\text { Slope }(0) \\
\text { Slope bottom }(1)\end{array}$ & \\
\hline Horizontal microtopography & $\begin{array}{l}\text { Extreme convexity }(-2) \\
\text { Convexity }(-1) \\
\text { Slope }(0) \\
\text { Concavity (1) } \\
\text { Extreme concavity (2) }\end{array}$ & \\
\hline Composite microtopography & $(-3,3)$ & $\begin{array}{l}\text { Calculated as the sum of horizontal and vertica } \\
\text { microtopography: negative values for } \\
\text { convexity, } 0 \text { for slope, positive values for } \\
\text { concavity }\end{array}$ \\
\hline
\end{tabular}


test consists in dipping the sample end where the sapwood area was measured in soapy water and blowing on the other sample end. The portion of the soapy cross section not forming bubbles, if any, is considered as heartwood. Where present, the proportion of heartwood was recorded and the correspondent area calculated using the ellipse formula as previously described. The sapwood area $\left(A_{\mathrm{s}}\right)$ was then calculated by subtracting the heartwood portion from the cross-sectional area.

$A_{\mathrm{L}}: A_{\mathrm{S}}$ was calculated dividing the total leaf area $\left(A_{\mathrm{L}}\right)$ by the corresponding sapwood area $\left(A_{\mathrm{S}}\right)$ for each branch. For trees where two branches were collected, $A_{\mathrm{L}}: A_{\mathrm{S}}$ was calculated as the mean of both values. The transformation for calculating the theoretical ground-level $A_{\mathrm{L}}: A_{\mathrm{Sground}}$ was achieved using the formula proposed by Gehring et al. (2015) for the study region, that is, $A_{\mathrm{L}}: A_{\mathrm{Sground}}=A_{\mathrm{L}}$ :$A_{\mathrm{S}}+0.0282$ height $_{\text {branch }}$.

The data set was treated as unique, since no significant interannual $A_{\mathrm{L}}: A_{\mathrm{S}}$ variation was detected ( $p>0.05$, nonparametric Mann-Whitney $U$ test, data not shown).

The analyses were performed separately for both $A_{\mathrm{L}}: A_{\mathrm{S}}$ and $A_{\mathrm{L}}: A_{\text {Sground. }}$. Data were first explored with univariate comparative analyses on the categorized explanatory variables (non-parametric Mann-Whitney $U$ test). In the case of highly correlated variables (Pearson $R>0.6$ ) expressing the same biological meaning, we retained the more pertinent ones from a physiological (ease of interpretation) and practical (easiness and precision to be collected in the field) point of view. Linear regression analyses were then used to model the relationship of the explanatory variables to $A_{\mathrm{L}}: A_{\mathrm{S}}$ and $A_{\mathrm{L}}: A_{\mathrm{Sground}}$, respectively. To keep models simple and easy to interpret, we decided not to include interaction terms (Chambers et al. 1992). Since some dendrometric characteristics may already represent the tree response to the environmental conditions, we split the explanatory variables into two groups for the analysis: dendrometric and environmental parameters. We then performed the model selection on the two variable groups separately (dendrometric and environmental) as well on the whole variables set (dendrometric-environmental) (Table 2). Model multicollinearity was checked according to Belsley et al. (1980) that is looking for variation inflation factors smaller than 5 and condition indices smaller than 30 . Only models without multicollinearity issues were retained choosing the best ones on the basis of the AICc coefficient (Akaike information criterion with a second-order correction for small sample size). We evaluated the goodness of fit of selected model by the means of the coefficient of determination (adjusted $R^{2}$ ), ranking then the relative contribution of each predictor according to the corresponding $t$ values.
All statistical analyses were performed using the $\mathrm{R}$ statistical package version 3.2.2 (R Development Core Team 2015).

\section{Results}

The analyses performed with $A_{\mathrm{L}}: A_{\mathrm{S}}$ and $A_{\mathrm{L}}: A_{\text {Sground }}$ showed similar results, the latter being always more significant.

$A_{\mathrm{L}}: A_{\mathrm{S}}$ varied within the sampled trees by a factor of 8.4 (min $0.12, \max 1.01$ ) and the transformed $A_{\mathrm{L}}: A_{\text {Sground }}$ by a factor of 4.7 (0.29-1.35).

The distributions of the $A_{\mathrm{L}}: A_{\mathrm{S}}$ and $A_{\mathrm{L}}: A_{\mathrm{Sground}}$ values with respect to the environmental variables highlight the significant effect of combined microtopography (Fig. 2a, c), slope (Fig. 2b, d), and distance to the next water channel (see Fig. S2a,d in Online resource 1).

The best full $A_{\mathrm{L}}: A_{\mathrm{S}}$ and $A_{\mathrm{L}}: A_{\text {Sground }}$ environmental model retains only composite microtopography $\left(t\right.$ value $=6.35, t$ value $\left._{\text {ground }}=11.55\right)$ as explanatory variable and reaches an adjusted $R^{2}$ value of 0.33 and of 0.62 respectively (Table 3 , Model $E, E_{\text {ground }}$ ).

The distribution of the $A_{\mathrm{L}}: A_{\mathrm{S}}$ and $A_{\mathrm{L}}: A_{\mathrm{Sground}}$ values with respect to the dendrometric variables shows a positive significant effect with tree height (Fig. 3a, c), DBH (see Fig. S2b,e in Online Resource 1), and crown base height (see Fig. S2c, f in Online Resource 1) and negative with crown portion at light (Fig. 3b, d). In both the cases, the best full models based on dendrometric variables include tree height $(t$ value $=2.69$, $t$ value $_{\text {ground }}=11.62$ ) and the crown exposure to light $\left(t\right.$ value $=-2.69, t$ value $\left._{\text {ground }}=-2.84\right)$ and have an adjusted $R^{2}$ of 0.15 and of 0.65 for the model with $A_{\mathrm{L}}: A_{\mathrm{S}}$ and $A_{\mathrm{L}}$ :$A_{\text {Sground }}$, respectively (Table 3 , Model $D$ and $D_{\text {ground }}$ ).

The best full model with $A_{\mathrm{L}}: A_{\mathrm{S}}$ as the response variable considering all variables (dendrometric and environmental) includes light exposure of the crown, composite microtopography, and slope $(t$ value $=-1.65,5.55$, and 1.17 respectively), reaching an adjusted $R^{2}$ of 0.31 (Table 3, Model $D-E$ ) and performing slightly better with respect to the exclusively environmental model (Table 3, Model $E$ ) and much better with respect to the dendrometric model (Table 3, Model $D$ ). On the other hand, the best full model with $A_{\mathrm{L}}: A_{\text {Sground }}$ as the response variable includes also the variable height ( $t$ value $=6.17$ ), in addition to light exposure of the crown, composite microtopography, and slope ( $t$ value $=-1.62,5.36$ and 0.98$)$, reaching an adjusted $R^{2}$ of 0.74 . The model performs better than the exclusively environmental or dendrometric models.

The variance inflation factors range from 1.01 to 2.17 in all models, and the highest condition index is equal to 7.9, suggesting that multicollinearity is not an issue and that the 
Fig. 2 Boxplots of $A_{\mathrm{L}}: A_{\mathrm{S}}(\mathbf{a}$, b) and $A_{\mathrm{L}}: A_{\text {Sground }}(\mathbf{c}, \mathbf{d})$ for Castanea sativa, according to microtopography composite index (a, c) and slope (b, d). Letters indicate significant differences with $p<0.05$ according to the non-parametric Mann-Whitney $U$ test with Holm adjustment. Labels on the top $(n)$ represent the number of sampled trees for each category

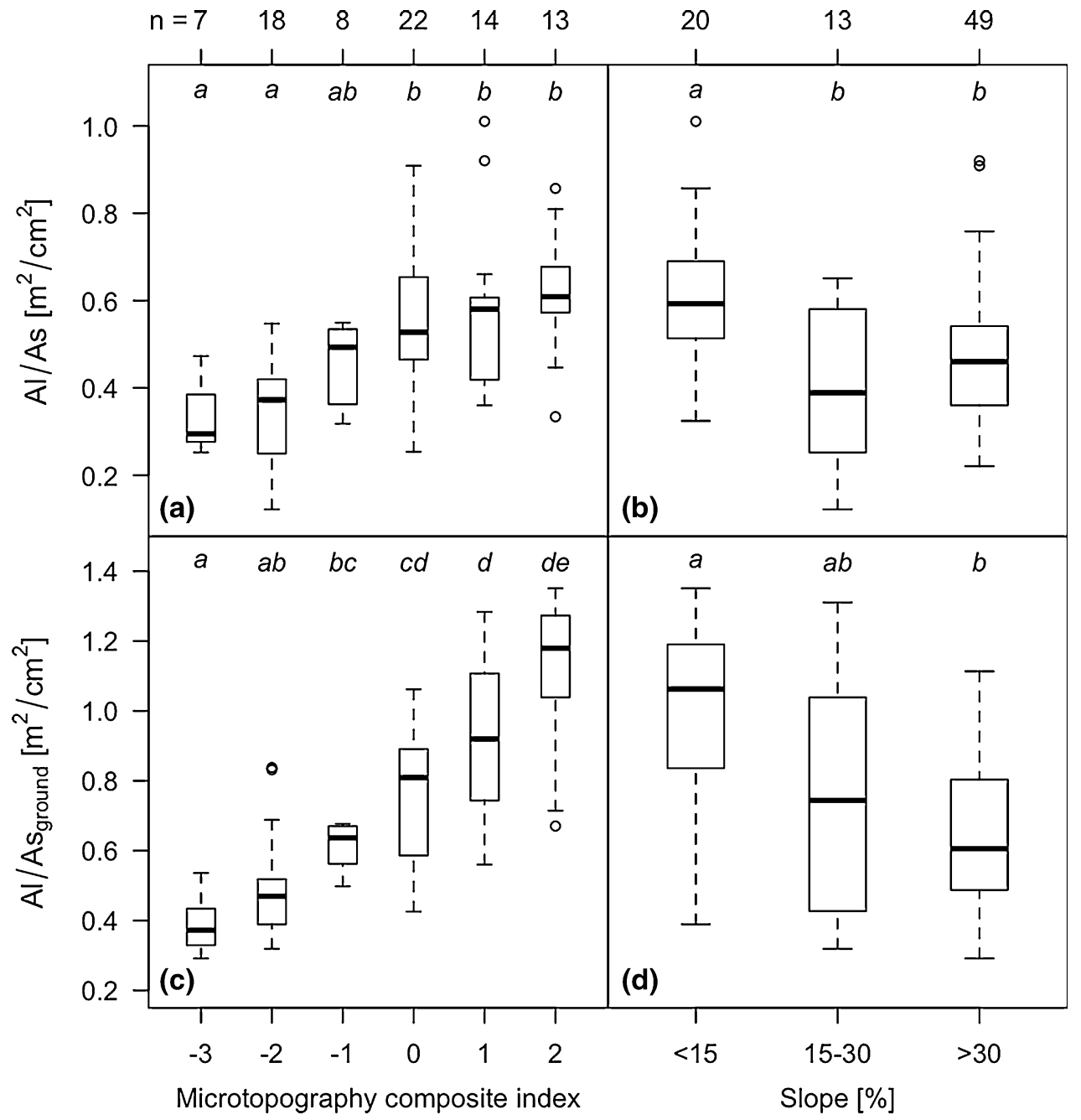

main environmental and dendrometric response variables are complementary and not collinear. Moreover, graphical examinations of linear models assumptions do not suggest any violation.

\section{Discussion}

Our data show that the investigated leaf-to-sapwood area ratios $\left(A_{\mathrm{L}}: A_{\mathrm{S}}\right.$ and $\left.A_{\mathrm{L}}: A_{\text {Sground }}\right)$ decrease in water-stressed habitats and/or light-exposed conditions. Moreover, both the ratios show a significant decreasing trend between the small trees growing on extreme water-poor sites and the tall trees on water-rich sites. This is a strong evidence of an environmental-induced effect when considering that the within-tree untransformed $A_{\mathrm{L}}: A_{\mathrm{S}}$ usually decreases with tree height as reported for the same species and the same study area by Gehring et al. (2015).

This change in biomass allocation may contribute to the maintaining of water flow from root to leaf by supplying greater hydraulic capacity per unit of leaf area, as postulated by the pipe model principle (Shinozaki et al. 1964a, b). It seems therefore reasonable to assume that the balance between water availability and evaporative demand is one of the main factors influencing the $A_{\mathrm{L}}: A_{\mathrm{S}}$ ratio. Our results further strengthen the hypothesis that the water balance at the growing site is likely to influence the biomass partitioning of plants and trees in particular.

The obtained values' range of leaf-to-sapwood area ratios along a gradient from supposed water-rich (concave position and nearer to waterbeds) to water-stressed sites (convex, steeper slopes) in chestnut trees is as double as the variability of the $A_{\mathrm{L}}: A_{\mathrm{S}}$ values as reported for even-aged Populus euramericana (Mazzoleni 1990) growing on different site conditions.

The regulating role of microtopography on tree water balance is in line with the dominant soil characteristics as described by Blaser (1973) for the study region. The high drainage capacity of the podsolic sandy soils in the study area makes soil water availability highly dependent on the 
Table 3 Best AICc linear models considering all variables $(D-E=$ dendro-environmental), or separately with dendrometric $(D)$ and environmental $(E)$ variables

\begin{tabular}{|c|c|c|c|c|c|c|c|c|c|}
\hline Model & Variables & Estimate & $t$ value & $\log _{\text {Lik }}$ & $S_{\text {resid }}^{2}$ & $S_{\text {resid }}$ & $\mathrm{AIC}_{\mathrm{c}}$ & $R^{2}$ & Adj. $R^{2}$ \\
\hline \multirow[t]{2}{*}{ E } & Intercept & 0.5120 & 31.39 & 43.00 & 0.021 & 0.144 & -79.70 & 0.34 & 0.33 \\
\hline & Comp. microtopography & 0.0649 & 6.35 & & & & & & \\
\hline \multirow[t]{2}{*}{$E_{\text {ground }}$} & Intercept & 0.7835 & 39.14 & 26.22 & 0.031 & 0.177 & -46.13 & 0.63 & 0.62 \\
\hline & Comp. microtopography & 0.1448 & 11.55 & & & & & & \\
\hline \multirow[t]{3}{*}{$D$} & Intercept & 0.5189 & 10.10 & 33.98 & 0.026 & 0.161 & -59.43 & 0.17 & 0.15 \\
\hline & Crown exp. light & -0.0017 & -2.69 & & & & & & \\
\hline & Height & 0.0072 & 2.69 & & & & & & \\
\hline \multirow[t]{3}{*}{$D_{\text {ground }}$} & Intercept & 0.5204 & 9.65 & 30.08 & 0.028 & 0.169 & -51.64 & 0.66 & 0.65 \\
\hline & Crown exp. light & -0.0018 & -2.84 & & & & & & \\
\hline & Height & 0.0330 & 11.62 & & & & & & \\
\hline \multirow[t]{4}{*}{$D-E$} & Intercept & 0.5394 & 12.65 & 45.04 & 0.020 & 0.141 & -79.29 & 0.37 & 0.34 \\
\hline & Slope & 0.0007 & 1.17 & & & & & & \\
\hline & Comp. microtopography & 0.0665 & 5.55 & & & & & & \\
\hline & Crown exp. light & -0.0009 & -1.65 & & & & & & \\
\hline \multirow[t]{5}{*}{$D-E_{\text {ground }}$} & Intercept & 0.5800 & 9.79 & 43.08 & 0.021 & 0.144 & -73.04 & 0.75 & 0.74 \\
\hline & Slope & 0.0006 & 0.98 & & & & & & \\
\hline & Comp. microtopography & 0.0822 & 5.36 & & & & & & \\
\hline & Crown exp. light & -0.0009 & -1.62 & & & & & & \\
\hline & Height & 0.0214 & 6.17 & & & & & & \\
\hline$N$ & Intercept & 0.4923 & 25.22 & 26.26 & 0.031 & 0.177 & -48.37 & 0.00 & 0.00 \\
\hline$N_{\text {ground }}$ & Intercept & 0.7394 & 23.18 & -14.00 & 0.083 & 0.289 & 32.15 & 0.00 & 0.00 \\
\hline
\end{tabular}

$\mathrm{N}$ represents the null model with intercept only. The "ground" suffix indicates that the response variable is AL:AS ground

topography (Blaser et al. 2005) and partially on slope (as proposed by Grier and Running 1977). Trees growing on rocky ridges, ridges, and steep slopes may suffer from water deficit even in periods with regular rainfall because of the poor water retention capacity of the soil. This may be a critical issue especially during the phenological phase of leave unfolding and deploying which represent the first physiological process affected by water deficiency (Kramer 1983; Schulte et al. 1986; Mazzoleni and Dickmann 1988). These hypotheses are strengthened by the results of the environmental and dendrometric-environmental model selections, having in the best models microtopography as the most relevant variable (higher $t$ value) and secondarily the terrain slope (Table 3, Model $D-E$ ).

The resulting multiannual equilibrium of $A_{\mathrm{L}}: A_{\mathrm{S}}$ ratios not only reflects the microtopography-related soil water availability, but also the tree-growing conditions on the site as indicated by the relationship between the $A_{\mathrm{L}}: A_{\mathrm{S}}$ ratios and the dendrometric parameters, such as height, $\mathrm{DBH}$, and crown base height of mature trees. In fact, smaller and thinner trees were often situated on convex/drier sites, where they grow under low competition that enable them to keep the lower part of the crown active all lifelong.
Furthermore, the percentage of crown exposure to light gives a more complete picture of the overall water balance accounting for the evaporative stress caused by the direct sun exposure of the crown. Trees with higher crown exposure to light display an increased transpirational water loss and a correspondent lower leaf-to-sapwood area ratio (e.g., Grier and Running 1977; Jose and Gillespie 1996). Finally, from the results of the best dendrometric and dendrometric-environmental models, it seems that tree height and crown exposure to light are the most influent dendrometric variables, the first accounting for more variability in all $A_{\mathrm{L}}: A_{\text {Sground }}$ models (higher $t$ values) and the second for the $A_{\mathrm{L}}: A_{\mathrm{S}}$ models (higher or equal $t$ values in the dendrometric model).

The observed response of biomass allocation to water availability and evaporative demand is consistent with the previous studies showing a dependency of the $A_{\mathrm{L}}: A_{\mathrm{S}}$ ratio to climate (Mencuccini and Bonosi 2001; Poyatos et al. 2007; Martinez-Vilalta et al. 2009), to site conditions (Mazzoleni 1990; Mencuccini and Grace 1994; Sterck et al. 2008), as well as to evaporative demand (Waring et al. 1982; Mencuccini and Grace 1994) or vapour pressure deficit (DeLucia et al. 2000). 
Fig. 3 Boxplots of $A_{\mathrm{L}}: A_{\mathrm{S}}(\mathbf{a}$, b) and $A_{\mathrm{L}}: A_{\text {Sground }}(\mathbf{c}, \mathbf{d})$ for Castanea sativa, according to height of the trees $(\mathbf{a}, \mathbf{c})$ and crown exposure to light $(\mathbf{b}, \mathbf{d})$. Letters indicate significant differences with $p<0.05$, according to the non-parametric Mann-Whitney $U$ test with Holm adjustment. Labels on the top $(n)$ represent the number of sampled trees in each category

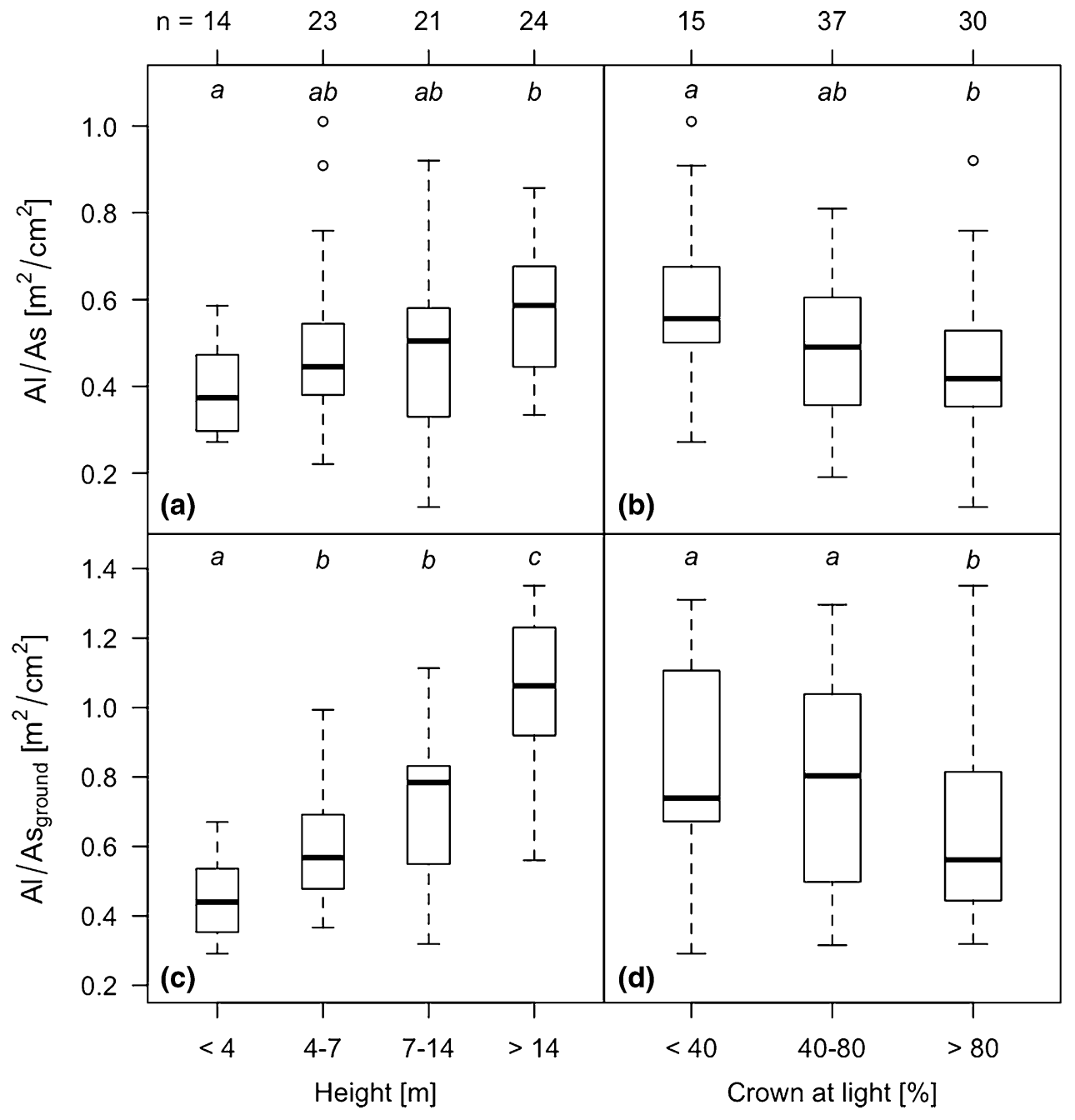

Regarding the branch height-transformed $A_{\mathrm{L}}: A_{\text {Sground }}$, this study confirmed the utility and the validity of the approach proposed by Gehring et al. (2015) for comparing trees growing in extremely different site conditions. The analysis of $A_{\mathrm{L}}: A_{\mathrm{S}}$ and $A_{\mathrm{L}}: A_{\text {Sground }}$ showed qualitatively similar results, but models with $A_{\mathrm{L}}: A_{\mathrm{S}}$ had a much smaller explicative power $\left(R^{2}<0.34\right)$ compared to those with $A_{\mathrm{L}}: A_{\text {Sground }}$, which displayed high coefficients of determination $\left(R^{2}>0.62\right)$. This lets us assume that the applied transformation does not skew the results but remove the masking effect due to the great variability in the sampling height of the branches.

From an applied point of view, the results presented in this study may improve our understanding of the stool uprooting phenomena in over-aged chestnut coppices as reported by several authors for northern Italy and southern Switzerland (e.g., Pividori et al. 2008). As pointed out in earlier studies (Vogt et al. 2006; Conedera et al. 2009), uprooting stools are mostly located in concave, water-rich microtopographies, where our study found higher values for the $A_{\mathrm{L}}: A_{\mathrm{S}}$ and $A_{\mathrm{L}}: A_{\mathrm{Sground}}$ ratios. It appears reasonable to postulate that the unbalance between oversized aerial biomasses and root systems causing the uprooting is reached sooner or prevalently in water-rich concave sites, what may confirm the hypothesis of a proportionality between the leaf-to-sapwood area ratio and the above-tobelow ground biomass ratio (Mazzoleni 1990). Using the $A_{\mathrm{L}}: A_{\mathrm{S}}$ and $A_{\mathrm{L}}: A_{\text {Sground }}$ ratios as proxies for above and below ground biomass partitioning has to be further investigated and confirmed, but could result in an important factor to be considered for the assessment and modelling of stand and slope stability in mountain areas (Schwarz et al. 2010; Schwarz et al. 2012).

\section{Conclusions}

The relationship $\left(A_{\mathrm{L}}: A_{\mathrm{S}}\right)$ has been confirmed to be a useful instrument to assess the ecological plasticity and thus the ability of a species to establish in sites with different 
characteristics, and differences in water availability in particular. Furthermore, the theoretical $A_{\mathrm{L}}: A_{\text {Sground }}$ represents a suitable measure for making the $A_{\mathrm{L}}: A_{\mathrm{S}}$ ratio a comparable hydraulic parameter among individuals of the same tree species. Further studies are on contrary necessary to verify if the ratio between leaf and sapwood areas may also be considered a proxy for the relationship between the aerial and the ipogeic biomass of the corresponding trees.

Author contribution statement $\mathrm{PGB}, \mathrm{CM}$, and MS originally formulated the concept of the study and with GE decided the sampling design. KP conceived the leaf area measurement and the image analysis and PGB developed and managed the database. GE conducted the fieldwork and performed the statistical analyses with PGB. GE wrote the manuscript, which was revised by PGB, MS, and CM. $\mathrm{ZM}$ computed the analysis for the aridity index. $\mathrm{CM}$ coordinated the research project and provided funds.

Acknowledgments Our heartfelt thanks go to Franco Fibbioli, Nora Buletti, and Susan Lagger for their help during data collection.

\section{Compliance with ethical standards}

Funding For this study, we only used our internal resources.

Conflict of interest The authors declare that they have no conflict of interest.

\section{References}

Beccaro GL, Torello-Marinoni D, Binelli G, Donno D, Boccacci P, Botta R, Cerutti AK, Conedera M (2012) Insights in the chestnut genetic diversity in Canton Ticino (Southern Switzerland). Silvae Genet 6:292-300

Beers TW, Dress PE, Wensel LC (1966) Aspect transformation in site productivity research. J Forest 64:691-692

Belsley DA, Kuh E, Welsch RE (1980) Regression diagnostics: identifying influential data and sources of collinearity. Wiley, New York

Blaser P (1973) Die Bodenbildung auf Silikatgesteinim südlichen Tessin. Mitt Eidgenöss Forsch anst Wald Schnee Landsch 49:251-340

Blaser P, Zimmermann S, Luster J, Walthert L, Lüscher P (2005) Waldböden der Schweiz, vol 2. Birmensdorf, Eidgenössische Forschungsanstalt WSL, Bern, Hep Verlag, Regionen Alpen und Alpensüdseite 920 p

Bonan G (2002) Ecological climatology. Concepts and applications. Cambridge University Press, Cambridge

Callaway RM, Sala A, Keane RE (2000) Succession may maintain high leaf area: Sapwood ratios and productivity in old subalpine forests. Ecosystem 3:254-268

Chambers JM, Hastie TJ (1992) Statistical Models in S. Chapman \& Hall, London

Conedera M, Krebs P (2008) History, present situation and perspective of chestnut cultivation in Europe. Acta Hortic 784:23-27

Conedera M, Manetti MC, Giudici F, Amorini E (2004) Distribution and economic potential of the sweet chestnut (Castanea sativa Mill.) in Europe. Ecol Medit 30:179-193

Conedera M, Fonti P, Nicoloso A, Meloni F, Pividori M (2009) Ribaltamento delle ceppaie di castagno: individuazione delle zone a rischio e proposte selvicolturali. Sherwood 154:15-18
Conedera M, Barthold F, Torriani D, Pezzatti GB (2010) Drought sensitivity of Castanea sativa: case study of summer 2003 in the southern alps. Acta Hortic (ishs) 866:297-302

Cruiziat P, Cochard H, Ameglio T (2002) Hydraulic architecture of trees: main concepts and results. Ann Forest Sci 59:723-752

Dai A (2012) Increasing drought under global warming in observations and models. Nat Clim Change 3:52-58

Delucia EH, Maherali H, Carey EV (2000) Climate-driven changes in biomass allocation in pines. Global Change Biol 6:587-593

Fernandez-Lopez J, Zas R, Diaz R, Villani F, Cherubini M, Aravanopoulos FA, Alizoti PG, Eriksson G, Botta R, Mellano MG (2005) Geographic variability among extreme European wild chestnut populations. Acta Hortic 693:181-186

Gehring E, Pezzatti GB, Krebs P, Mazzoleni S, Conedera M (2015) On the applicability of the pipe model theory on the chestnut tree (Castanea sativa Mill.). Trees Struct Funct 29:321-332

Grier CG, Running SW (1977) Leaf area of mature northwestern coniferous forests: relation to site water balance. Ecology $58: 893-899$

Hoadley RB (1980) Understanding wood: a craftsman's guide to wood technology. Taunton Press Inc, USA

Hoffmann AA, Sgrò CM (2011) Climate change and evolutionary adaptation. Nature 470:479-485

Jose S, Gillespie AR (1996) Above ground production efficiency and canopy nutrient contents of mixed-hardwood forest communities along a moisture gradient in the central United States. Can J Forest Res 26:2214-2223

Kramer PJ (1983) Water relations of plants. Academic Press, USA

Krebs P, Koutsias N, Conedera M (2012) Modelling the eco-cultural niche of giant chestnut trees: new insights into land use history in southern Switzerland through distribution analysis of a living heritage. J Hist Geogr 38:372-386

Lauteri M, Scartazza A, Guido MC, Brugnoli E (1997) Genetic variation in photosynthetic capacity, carbon isotope discrimination and mesophyll conductance in provenances of Castanea sativa adapted to different environments. Funct Ecol 11:675-683

Lauteri M, Pluira A, Monteverdi MC, Brugnoli E, Villani F, Eriksson $\mathrm{G}$ (2004) Genetic variation in carbon isotope discrimination in six European populations of Castanea sativa Mill. originating from contrasting localities. J Evol Biol 17:1286-1296

Maherali H, Pockman WT, Jackson RB (2004) Adaptive variation in the vulnerability of woody plants to xylem cavitation. Ecology 8:2184-2199

Martin MA, Mattioni C, Cherubini M, Taurchini D, Villani F (2010) Genetic diversity in European chestnut populations by means of genomic and genic microsatellite markers. Tree Genet Genomes 6:735-744

Martinez-Vilalta J, Cochard H, Mencuccini M, Sterck F, Herrero A, Korhonen JFJ, Llorens P, Nikinmaa E, Nole A, Poyatos R, Ripullone F, Sass-Klaassen U, Zweifel R (2009) Hydraulic adjustment of Scots pine across Europe. New Phytol 184:353-364

Mattioni C, Cherubini M, Micheli E, Villani F, Bucci G (2008) Role of domestication in shaping Castanea sativa genetic variation in Europe. Tree Genet Genomes 4:563-574

Mattioni C, Martin MA, Pollegioni P, Cherubini M, Villani F (2013) Microsatellite markers reveal a strong geographical structure in European populations of Castanea sativa (Fagaceae), Evidence for multiple glacial refugia. Am J Bot 100:951-961

Mazzoleni S (1990) Relazioni tra aree fogliarie e superfici di conduzione nel fusto nell'analisi di gradienti ambientali. Linea Ecol, pp 27-30

Mazzoleni S, Dickmann DI (1988) Differential physiological and morphological responses of two hybrid Populus clones to water stress. Tree Physiol 4:61-70 
Mencuccini M, Bonosi L (2001) Leaf/sapwood area ratios in Scots pine show acclimation across Europe. Can J Forest Res 31:442-456

Mencuccini M, Grace J (1994) Climate influences the leaf area/ sapwood area ratio in Scots pine. Tree Physiol 15:1-10

Parmesan C (2006) Ecological and evolutionary responses to recent climate change. Annu Rev Ecol Evol Syst 37:637-669

Pividori M, Meloni F, Nicoloso A, Arienti R, Conedera M (2008) Ribaltamento delle ceppaie di castagno due casi di studio in cedui invecchiati Sherwood 14:17-21

Poyatos R, Martinez-Vilalta J, Cermak J, Ceulemans R, Granier A, Irvine J, Kostner B, Lagergren F, Meiresonne L, Nadezhdina N, Zimmermann R, Llorens P, Mencuccini M (2007) Plasticity in hydraulic architecture of Scots pine across Eurasia. Oecologia 153:245-259

Schlichting CD (1986) The evolution of phenotypic plasticity in plants. Annu Rev Ecol Syst 17:667-693

Schulte PJ, Hinckley TM, Stettler RF (1986) Stomatal response of Populus to leaf water potential. Can J Bot 65:255-260

Schwarz M, Lehmann P, Or D (2010) Quantifying lateral root reinforcement in steep slopes-from a bundle of roots to tree stands. Earth Surf Process Landf 35:354-367

Schwarz M, Cohen D, Or D (2012) Spatial characterization of root reinforcement at stand scale: theory and case study. Geomorphology 171-172:190-200

Shinozaki K, Yoda K, Hozumi K, Kira T (1964a) A quantitative analysis of plant form-the pipe model theory. I. Basic analyses. Jpn J Ecol 14:97-105

Shinozaki K, Yoda K, Hozumi K, Kira T (1964b) A quantitative analysis of plant form-the pipe model theory. II. Further evidence of the theory and its application in forest ecology. Jpn J Ecol 14:133-139

Spinedi F, Isotta F (2004) Il clima del Ticino. Dati statistiche e società 2:5-39

Sterck JS, Zweifel R, Sass-Klaassen U, Chowdhury Q (2008) Persisting soil drought reduces leaf specific conductivity in Scots pine (Pinus sylvestris) and pubescent oak (Quercus pubescens). Tree Physiol 28:529-536

UNEP-United nations environment programme (1992) In: Middleton N, Thomas DSG (eds) World atlas of desertification. Edward Arnold, London. ISBN 0340555122

Vertessy RA, Benyo RG, O'Sullivan SK, Gribben PR (1995) Relationships between stem diameter, sapwood area, leaf area and transpiration in a young mountain ash forest. Tree Physiol 15:559-567

Villani F, Pigliucci M, Lauteri M, Cherubini M, Sun O (1992) Congruence between genetic, morphometric and physiological data on differentiation of Turkish chestnut (Castanea sativa). Genome 35:251-256

Vogt J, Fonti P, Conedera M, Schröder B (2006) Temporal and spatial dynamic of stool uprooting in abandoned chestnut coppice forests. For Ecol Manage 235(1-3):88-95

Waring RH, Schroeder PE, Oren R (1982) Application of the pipe model theory to predict canopy leaf-area. Can J Forest Res 12:556-560

Whitehead D, Edwards WRN, Jarvis PG (1984) Conducting sapwood area, foliage area and permeability in mature trees of Picea sitchensis and Pinus contorta. Can J Forest Res 14:940-994 